Original Research Article

\title{
Evaluation of antidiabetic activity of fruit of Coriandrum sativum. Linn methanolic extract in Streptozocin induced diabetic wistar Albino rats
}

\author{
Ahmed S. K. ${ }^{1}$, Chakrapani Cheekavolu ${ }^{2 *}$, Sampath D. ${ }^{3}$, Sunil M. ${ }^{4}$
}

${ }^{1}$ Department of Pharmacology, Shadan Institute of Medical Sciences (SIMS), Hyderabad, Telangana, India

${ }^{2}$ Department of Pharmacology, Kerala Medical College and Hospital, Mangode, Palakkad, Kerala, India

${ }^{3}$ Department of Pharmacology, P.E.S. Institute of Medical Sciences, Kuppam, Chittoor, Andhra Pradesh, india ${ }^{4}$ Department of Pharmacology, Maheshwara Medical College and Hospital, Isnapur, Patancheru, Medak, Telangana, India

Received: 19 October 2017

Revised: 31 October 2017

Accepted: 27 November 2017

*Correspondence to:

Dr. Chakrapani Cheekavolu, Email: chakri14783@gmail.com

Copyright: (C) the author(s), publisher and licensee Medip Academy. This is an openaccess article distributed under the terms of the Creative Commons Attribution NonCommercial License, which permits unrestricted noncommercial use, distribution, and reproduction in any medium, provided the original work is properly cited.

\begin{abstract}
Background: Diabetes prevalence is estimated to increase annually. Numerous people use traditional medicine, such as India also considered as the diabetic capital in the world. Diabetes is a metabolic disorder characterized by disturbances in lipid, carbohydrate and protein metabolism. The present study to evaluate the antidiabetic potential of coriandrum sativum. linn fruits methanolic extract in streptozocin induced diabetic wistar albino rats model.

Methods: Diabetes induction in wistar albino rats by administration of streptozocin $(50 \mathrm{mg} / \mathrm{kg}$, i.p.) in citrate buffer. 30 wistar albino rats were divided into 5 groups (A, B, C, D, E). Group A: served as normal control, whereas Group B: diabetic control, Group C, D methanolic coriandrum sativum Linn. fruits extract (CSFME) at a dose of $100,200 \mathrm{mg} / \mathrm{kg}$ orally, Group E was given standard drug Glibenclamide $(0.5 \mathrm{mg} / \mathrm{kg})$ orally. All groups are administered for the period of 14 consecutive days and blood sugar levels was measured at regular intervals up to end of the study.

Results: This present research study confirms that the test drug compound CSFME has sustained oral hypoglycaemic activity and statistically significant ( $\mathrm{p}$ $\leq 0.05$ ) and which is comparable with standard drug Glibenclamide.

Conclusions: This research study confirms that the CSFME has antidiabetic activity against streptozocin induced wistar diabetic albino rats. It could be a novel antidiabetic agent and also a dietary adjunct in the type 2 diabetes management and its complication. Further studies are necessary required to confirm the antidiabetic activity of individual phytochemical compounds of Coriandrum sativum.
\end{abstract}

Keywords: Antidiabetic, Blood glucose, Coriandrum sativum, Diabetic wistar albino rats, Glibenclamide, Methanolic extract

\section{INTRODUCTION}

Diabetes was described almost more than a 2000 years ago. For the past 200 years, it has featured in the modern medicines history and is a syndrome characterized by disordered metabolism and inappropriate hyperglycemia due to either the deficiency of insulin secretion or due to a combination resistance of insulin and inadequate secretion of insulin to compensate. ${ }^{1}$ A worldwide survey has reported that this diabetes affects almost nearly $10 \%$ of the 
world's population. It has been also predicted that diabetes prevalence in adults will increase from almost 135 million in 1995 to 350 million in 2030 as given by the International Diabetes Federation. ${ }^{2,3}$ The synthetic antidiabetic drugs Currently available produced some of the serious side effects like hypoglycemic coma and hepatorenal disturbances. ${ }^{4,5}$ Hence the patients are therefore using herbal medicines which possess few minor side effects and have the potential to impart therapeutic effect in complicated disorders like diabetes and its complication. ${ }^{6}$ Following the strong recommendations of WHO for research on the beneficial uses of medicinal herbal plants in diabetes treatment, investigations on hypoglycemic drugs derived from these medicinal herbal plants have also gained the momentum. Traditional medicinal plants with various biological active principles and properties have been used from ancient times by physicians and laymen to treat a great variety of human diseases such as the coronary heart disease (CHD), diabetes and cancer. Antidiabetic drugs from the medicinal plants could serve as a best source for drug design and much attention has been fixed on formulation of herbal medicine. ${ }^{7}$ Medicinal herbal plants are well known in traditional herbal medicine for their hypoglycemic activities and the available literature indicate that more than 800 medicinal plants species showing hypoglycemic activity. There has been increased demand of medicinal herbal plant products with their antidiabetic activity due to their easy availability, low cost and minute side effects. Therefore, the medicinal plant materials are regularly and continuously scrutinized and explored for their hypoglycemic effect as a hypoglycemic agents. Coriandrum sativum is one of such plant that has been used in the Indian traditional medicinal system for diabetes treatment.

Coriander (Coriandrum sativum Linn.) one of the most important medicinal herbal plant of Apiaceae family andis one of the most valuable medicinal and seasoning plant. This species comes from the Mediterranean region actually and is grown almost all over the world. The coriander fruit and essential oil isolated from it are used for medicinal purpose. ${ }^{8,9}$ Coriandrum is widely used in traditional herbal medicine to treat dizziness, headache, anxiety, digestive disorders, fever, edema, allergies, respiratory diseases, and burns. ${ }^{10,11}$ The fruits of coriander are used as stomachic, astringent, emollient, anthelmintic, antibilious, appetizer, digestive, constipating, antipyretic, refrigerant, diuretic, anodyne, tonic, expectorant, dyspepsia and antidiabetic. The phytochemical compound screening of Coriander has showed that it has contained terpenoids, tannins, essential oil, reducing sugars, flavonoids, alkaloids, phenolics, sterols, fatty acids and glycosides. It has also contained a high nutritional value including carbohydrates, proteins, oils, fibers and a huge number of vitamins, minerals and trace elements. The previous coriander pharmacological studies was revealed that coriander possessed antidepressant, anticonvulsant, anxiolytic, memory enhancement, sedative-hypnotic, orofacial dyskinesia improvement, antioxidant, neuroprotective, antibacterial, antifungal, insecticidal, anthelmintic, anti-inflammatory, hypolipidemic, cardiovascular, antidiabetic, analgesic, anticancer, diuretic, mutagenic, antimutagenic, detoxification, gastrointestinal, dermatological, deodorizing, reproductive and hepatoprotective and many other pharmacological effects. ${ }^{12-17}$ Silver nanoparticles of coriander were synthesized by using aqueous and methanolic extracts of Coriandrum fruit and its antioxidant effects were reported. ${ }^{18}$ In the light of the above information, the present research study investigation was under taken to evaluate the antidiabetic activity of Coriandrum sativum fruit using streptozocin (STZ) induced wistar diabetic albino rats model.

\section{METHODS}

\section{Chemicals}

Streptozocin (Hi-media labs Pvt. Ltd. (India). Tab glibenclamide, 5mg (Aventis Pharma Ltd, Ankles war), Diagnostic Kits (Roche, Mumbai), methanol, citrate buffer ( $\mathrm{pH} 4.5)$.

\begin{abstract}
Animals
30 Wistar Albino rats of both sex weighing weight between 150-200gm were used in this experiment. Animals were housed in a group of six (6) in the polypropylene cages at a controlled room temperature of $25 \pm 2^{\circ} \mathrm{C}$, relative humidity was $55 \%$ and $12 \mathrm{hrs}$. light: dark cycle. Animals were fed with supplied standard food pellet diet and water ad libitum during this experiment. Prior to this experiment the wistar albino rats were fasted for a exact time period of $12 \mathrm{hrs}$ with water ad libitum given and weighed. All study protocols were approved by CPCSEA and cleared by Institutional Animal Ethical Committee (IAEC) at Mamata Medical College, Khammam, Telangana state.
\end{abstract}

\section{Plant material and preparation of plant extract}

Coriandrum sativum Fruit were collected from local market in Khammam city at rotary nagar in the month of October - November and authenticated by Assistant Professor and Head, Department of Botany, Govt. SRBJNR PG College, Khammam. Coarsely powdered Coriandrum sativum fruits $200 \mathrm{~g}$ was extracted with $75 \%$ methanol $[1500 \mathrm{ml}]$ in a soxhlet extraction apparatus till the complete exhaustion, filtered. The methanolic extract was then concentrated by a rotary vacuum evaporator and evaporated to dryness. The solvent is then evaporated at room temperature to obtain reddish brown extract. This obtained extract was stored nearly at $2-8^{\circ} \mathrm{C}$ till further use.

\section{Experimental diabetes induction}

Wistar albino rats were fasted overnight and blood is collected from the tail vein of each groups rats before the treatment i.e., on 0 day(initial) and on $7^{\text {th }}$ day and on the $14^{\text {th }}$ day of the treatment. Blood serum was separated from 
the collected blood sample by centrifugation and was used for the blood sugar estimation.

Animals were fasted for a exact period of $12 \mathrm{hrs}$. before Diabetes induction. Diabetes induction in wistar albino rats was done by administration of freshly prepared streptozocin $(50 \mathrm{mg} / \mathrm{kg}$, i.p.). in citrate buffer. A freshly prepared single dose of streptozocin $(50 \mathrm{mg} / \mathrm{kg}$, i.p. $)$ was dissolved in citrate buffer and was used for type -2 diabetes induction in rats after overnight fasting. After $1 \mathrm{~h}$ of streptozocin administration, the wistar albino rats were fed with the standard food pellets and water ad libitum. The wistar albino rats were stabilized for a week and animals showing blood sugar levels more than $200 \mathrm{mg} / \mathrm{dL}$ were selected for this study.

\section{Experimental design}

30 wistar albino rats were divided in five (5) groups whereas group A remained non-diabetic and group B consist diabetic and group 3 and 4 consisting diabetic plus treated:

- Group A: Rats received saline (only saline $10 \mathrm{ml} / \mathrm{kg}$ / day) orally for an exact period of 14 days.

- Group B: Rats received streptozocin single dose $(50 \mathrm{mg} / \mathrm{kg}$, b.w., i.p.) (Hi-media laboratories Pvt. Ltd. (India)) dissolved in citrate buffer was used for type 2 diabetes induction in rats after overnight fasting.

- Group C: Rats received streptozocin single dose (50 $\mathrm{mg} / \mathrm{kg}$, b.w., i.p.) plus coriandrum sativum fruits methanolic extract suspension $(100 \mathrm{mg} / \mathrm{kg}$ b.w. in citrate buffer orally for an exact period of 14 days.

- Group D: Rats received streptozocin single dose (50 $\mathrm{mg} / \mathrm{kg}$, b.w., i.p.) plus coriandrum sativum fruits methanolic extract suspension $(200 \mathrm{mg} / \mathrm{kg}$ b.w. in citrate buffer orally for an exact period of 14 days.

- Group E: Rats received streptozocin single dose (50 $\mathrm{mg} / \mathrm{kg}$, b.w., i.p.) plus Glibenclamide suspension
$(0.5 \mathrm{mg} / \mathrm{kg}$ b.w. in citrate buffer orally for an exact period of 14 days.

After 30 minutes of the treatment, the rats of each group were given glucose $(5 \mathrm{gm} / \mathrm{kg})$ in distilled water orally and blood is collected before the experiment day i.e. on ( 0 day (initial day), on the $7^{\text {th }}$ day of the given test drug coriandrum sativum fruit methanolic extract and on $14^{\text {th }}$ day of treatment from rats of each group and blood sugar values were observed.

\section{Statistical analysis}

Results of biochemical analysis parameter like levels of blood glucose are reported as Mean \pm SD of six (6) animals in each group $(n=6)$. The data were subjected to ANOVA (one-way analysis of variance) for the multiple comparisons followed by Dunnett's test was applied for determining the statistical significance of difference in blood glucose. P values of less than $0.05(\mathrm{p}<0.05)$ were considered as statistically significant.

\section{RESULTS}

This present research investigation has revealed and confirms that the antidiabetic activity of coriandrum sativum fruits methanolic extract on intraperitoneal injection of streptozocin at the dose of $50 \mathrm{mg} / \mathrm{kg}$ b.w. caused significant increase in blood sugar levels in untreated groups (diabetic rat group) when compared to the control group was shown in (Table 1). Treatment of diabetic wistar albino rats with coriandrum sativum fruits methanolic extract for the period of 14 days caused a dose dependent steep drop in the blood sugar levels in diabetic wistar albino rats. Glibenclamide treated diabetic rats also showed significant $(\mathrm{P}<0.00)$ steep drop in blood sugar levels after 14 days of treatment as shown in (Table 1).

Table 1: Effect of Coriandrum sativam Linn. Fruit methonolic extract on fasting blood sugar level in streptozocine induced diabetic wistar rats.

\begin{tabular}{|llll|}
\hline Treated groups & \multicolumn{3}{l|}{ Fasting blood glucose (mg/dl) } \\
\hline & 0 day (initial) & $\mathbf{7}^{\text {th }}$ day & $\mathbf{1 4}^{\text {th }}$ day (final) \\
\hline Normal control (only saline $10 \mathrm{ml} / \mathrm{kg} / \mathrm{day})$ orally & $97.3 \pm 5.0$ & $99.5 \pm 3.2$ & $96.5 \pm 5.3$ \\
\hline Diabetic control streptozocin $(50 \mathrm{mg} / \mathrm{kg})$ in a single i.p. dose & $97 . \pm 7.7$ & $283.8 \pm 5.1$ & $277.3 \pm 4.5$ \\
\hline Diabetic+ CS Linn. fruits methanolic extract (100mg/kg/day) orally & $98.33 \pm 7.1$ & $282 . \pm 5.4^{*}$ & $197 \pm 2.5 .7 * *$ \\
\hline Diabetic+ CS Linn. fruits methanolic extract (200mg/kg/day) orally & $100.33 \pm 3.2$ & $276.7 \pm 3.4^{*}$ & $180.3 \pm 5.9^{* *}$ \\
\hline Diabetic+glibenclamide $0.5 \mathrm{mg} / \mathrm{kg} /$ day orally & $97.67 \pm 4.3$ & $266.5 \pm 5.6^{*}$ & $145.7 \pm 4.1 * *$ \\
\hline
\end{tabular}

All values are expressed in Mean \pm SD. Analyzed by one way ANOVA followed by Dunnet's test for multiple comparison tests. $*=p<0.05$ when compared to the normal control group (significant $p$ value)

$* *=p<0.00$ when compared to diabetic control group (Highly significant $\mathrm{p}$ value)

\section{DISCUSSION}

The effect of repeated oral administration of $75 \%$ of the C. sativum (CS) fruits methanolic extract on blood sugar levels in streptozotocin induced diabetic wistar albino rats is shown in Table 1 . Treatment with coriandrum sativum fruits methanolic extract at the dose of 100 and $200 \mathrm{mg} / \mathrm{kg}$ body weight for $1^{\text {st }}$ and 2 nd week exhibited a significant 
$(p<0.05)$ reduction in fasting blood glucose levels in streptozotocin induced diabetic wistar albino rats as compared to diabetic control group (Table 1). Blood sugar levels of diabetic wistar albino rats started decreasing from the first week of the drug treatment itself that was continued to maintain till $2^{\text {nd }}$ week, which was comparable to glibenclamide $0.5 \mathrm{mg} / \mathrm{kg}$.

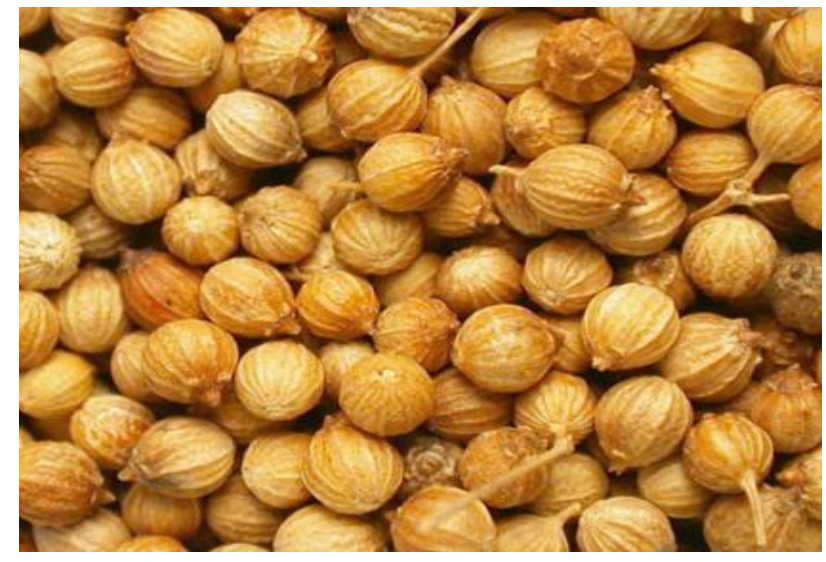

Figure 1: Coriandrum sativam linn. Fruit.

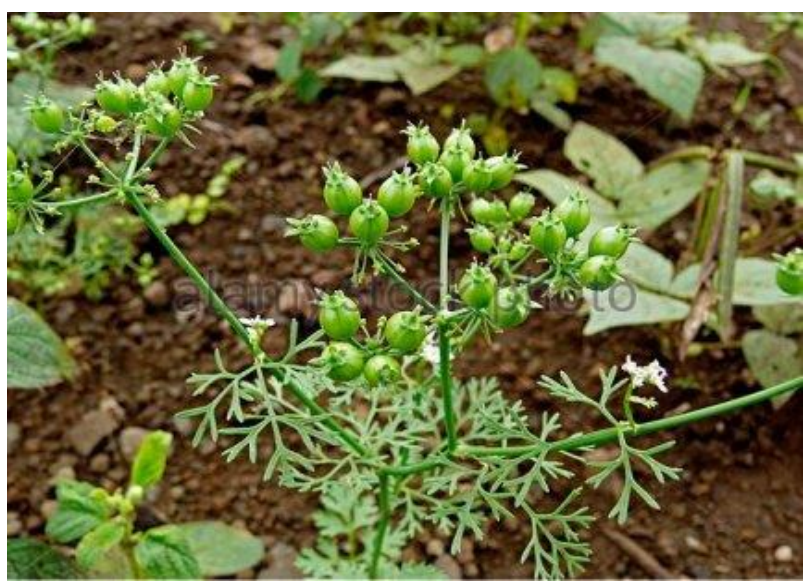

Figure 2: Coriandrum sativam linn. plant.

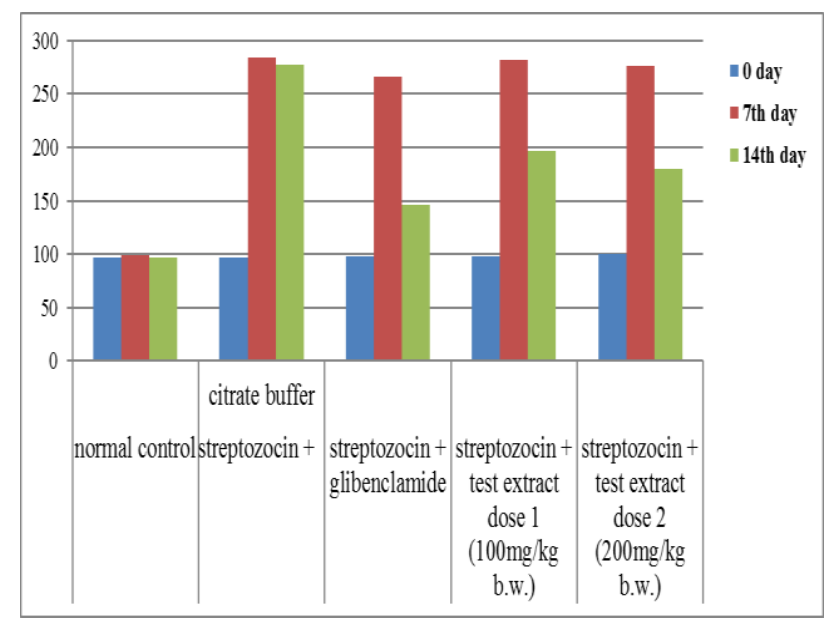

Figure 3. Blood glucose levels during experimental period (All treated groups).
In light of these results, our research study clearly indicates and confirms that the Coriandrum sativum Linn. fruits have antihyperglycemic effect significantly in Streptozocin (STZ) induced hyperglycaemic wistar albino rats. Streptozotocin was known to destroy the $\beta$-cells of the pancreas, which causes selective pancreatic islet $\beta$-cell cytotoxicity mediated through the nitric oxide (NO) release, methyl cations, methyl radicals, ROS (reactive oxygen species). This will results in a rapid reduction in concentration of pyridine nucleotide in pancreatic islet and the subsequent $\beta$-cell necrosis. The action of STZ on mitochondria generates SOD anions, which leads to diabetic mellitus complications. ${ }^{19-21}$

Glibenclamide, being as an Sulfonylurea derivative is often used as a standard antidiabetic drug in STZ-induced diabetes to compare the efficacy of a variety of antihyperglycemic drug compounds. Glibenclamide has been involved in stimulating insulin secretion from pancreatic $\beta$-cells principally by inhibiting ATP sensitive $\mathrm{K}^{+}$ATP channels in the plasma membrane. In our study, there was a significant rise in blood glucose level was perceived in diabetic control group as compared with normal albino rats. So, the CS1 (coriandrum sativum $100 \mathrm{mg} / \mathrm{kg}$ b.w.) and CS2 (coriandrum sativum $200 \mathrm{mg} / \mathrm{kg}$ b.w.) treated group albino rats exhibited significant decrease in fasting blood sugar levels as compared to the diabetic control group.

\section{CONCLUSION}

In this present research study, our experimental data findings clearly revealed and confirms that the test extract of our research study, i.e. coriandrum sativum. linn fruit methanolic extract at the dose of $100 \mathrm{mg} / \mathrm{kg}$ and $200 \mathrm{mg} / \mathrm{kg}$ b.w. possess potent antidiabetic activity. Thus, coriandrum sativum. linn fruit can be used as a potential antidiabetic agent. It could be a novel antidiabetic agent and also a dietary adjunct for the type 2 diabetes management and its complications. However, the exact mechanism of antidiabetic activity of coriandrum sativum linn. fruits methanolic extract is unknown. However, further confirmatory studies are still required to identify the probable mechanism of action to establish its antidiabetic action. Further human confirmatory studies are mandatory to findout the active component of coriandrum sativum. linn fruit and role of these herbal drugs in controlling diabetes and its complications.

\section{ACKNOWLEDGEMENTS}

Authors would like to thank to the Chairman, Mamata Medical College, Khammam, Telangana, for his guidance and encouragement. Whose kind heart cheered their efforts to process this research study properly, successfully to complete the task. Also, they are very much thankful to the Secretary, Principal and Head of the Pharmacology department and the staff members of the Mamata Medical College, Khammam and their parents, brothers and sister. The special thanks to Mr. D. Ramadasu, technician of 
experimental pharmacology, Mamata Medical College, Khammam. Last but not the least they express their gratitude to animals used in this study.

Funding: No funding sources

Conflict of interest: None declared

Ethical approval: The study was approved by the Institutional Ethics Committee

\section{REFERENCES}

1. Raheja BS, Kapor A, Bhaskar A, Sathe SR, Jorgensen LN, Moorthi SR. Diabetes care in India-current studies. JAPI. 2001;49(7):712-22.

2. Menaka CT, Ravirajsinh NJ, Ansarullah T, Ranjitsinh VD, Ramachnadran AV. Prevention of high fat diet induced insulin resistance in mice by Sida rhomboidea ROXB. Extract. J Health Sci. 2010;56:92-8.

3. Amos AF, McCarty, DJ, Zimmet P. The rising global burden of diabetes and its complications: estimates and projections by 2010. Diabet. Med. 1997;14(5):585 .

4. Sunil C, Latha PG, Suja SR, Shine VJ, Shyamal S, Anuja GI. Effect of ethanolic extract of Pisonia alba Span. leaves on blood glucose levels and histological changes in tissues of alloxan induced diabetic rats. Int J Appl Res Nat Prod. 2009;2:4-11.

5. Kyriacou A, Ahmed AB. Exenatide use in the management of type 2 diabetes mellitus. Pharmaceuticals. 2010;3:2554-67.

6. Pandita R, Phadke A, Jagtap A. Antidiabetic effect of Ficus religiosa extract in streptozotocin induced diabetic rats. J Ethnopharmacol. 2010;128(2):462-6.

7. Vishwakarma SL, Rakesh S, Rajani M, Goyal RK. Evaluation of effect of aqueous extract of Enicostemma littorale Blume in streptozotocin induced type 1 diabetic rats, Indian J. Exp. Biol. 2010;48:26-30.

8. The Wealth of India, First supplement Series-Raw Material] 2:Cl-Cy, National Institute of Science and Communication, Council of Scientific and Industrial Research, New Delhi, India; 2001:205.

9. Pullaih T. Encyclopedia of World Medicinal Plants, Vol 2, Regency Publication, New Delhi, India. 2006:1641.

10. Bently R, Trimen H. Medicinal Plants, Omsons Publications, New Delhi, India, 2002;2:729.

11. Khare PC. Indian Medicinal Plants, Springer Science Publishers, NY, USA; 2007:174.
12. Paarakh MP. Coriandrum sativum Linn: A review, Pharmacologyonline News Letters. 2009;3:561-73.

13. Paarakh MP, Rekha P, Dileep CS, Vedamurthy AB. HPTLC finger profile of Coriandrum sativum Linn. Research Journal of Pharmaceutical, Biological and Chemical Sciences. 2015;6(1):1407-15.

14. Sangeeta PB, Waseem R, Anil K. Dose dependent effect of Coriandrum sativum seeds on thermal pain stimuli. J Phyto. 2014;3(4):254-8.

15. Kamempor SF, Langenbez SV, Shajei MN, Ghorbani A, Pourganji M. The analgesic effect of different extracts of aerial parts of Coriandrum sativum in mice. Int J Biomed Sci. 2015;11(1):23-8.

16. Padmaa MP. Comparison of in vitro antioxidant activity of Coriandrum sativum fruit by soxhlation and maceration extraction technique, Eur J Biomed Pharm Sci. 2014;1:230-40.

17. Padmaa MP, Jai KS, Rupesh M. Analgesic activity of methanol extract of Coriandrum sativum Linn fruit. World Journal of Pharmacy and Pharm Sci. 2016;5(10):1456-64.

18. Padmaa MP. Green synthesis of silver nanoparticles using fruits of Coriandrum sativum Linn and its antioxidant activity. Journal of Natural Products and Resources. 2015;1(1):19-22.

19. Yadav JP, Saini S, Kalia AN, Dangi AS. Hypoglycemic and hypolipidemic activity of ethanolic extract of Salvodora oleoides in normal and alloxaninduced diabetic rats. Indian Journal of Pharmacology. 2008;40(1):23-7.

20. Papaccio G, Pisanthi FA, Latronico MY, Ammendola E, Galdieri M. Multiple low dose and single high dose treatments with streptozotocin do not generate nitric oxide. J of Cellular Biochemistry. 2000;77:82-91.

21. Anderson T, Schein PS, McMenamin MG, Cooney DA. Streptozotocin diabetes correlation with extent of depression of pancreatic islet nicotinamide adenine dinucleotide. Journal of Clinical Investigation. 1974;54:672-7.

Cite this article as: Ahmed SK, Cheekavolu C, Sampath D, Sunil M. Evaluation of antidiabetic activity of fruit of Coriandrum sativum. Linn methanolic extract in Streptozocin induced diabetic wistar Albino rats. Int J Basic Clin Pharmacol 2018;7:121-5. 